\title{
Standards for Library Automation and ISAD's Committee on Technical Standards for Library Automation (TESLA)
}

The role of ISAD's Committee on Technical Standards for Library Automation is examined and discussed. A procedure for the reaction to and initiation of standards is described, with reference to relevant standards organizations.

The development, implementation, and maintenance of standards might best be characterized as the complexity of simplification-complex insofar as a standard represents a universally applicable ideal which is usually the result of arduous negotiation and compromise; simplification since a standard, once recommended and followed in practice, forms a firm reference point for the achievement of specified objectives. Thus, if a standard exists, it can be referenced or used immediately and variant wheels do not have to be invented.

Unfortunately, to use, reference, or advocate a standard requires an awareness of available standards or the process whereby standards evolve. It is at this point that standards again become complex-in fact, they become a maze, which perhaps can be characterized by questions such as: Is there a standard already? Who is responsible for it? Where are copies of this standard available? and so on (a maze familiar, certainly, to all of us).

It is precisely to address the mazelike aspect of the standards "game" that the Committee on Technical Standards for Library Automation (TESLA) has been established. In short, TESLA intends to act as a twoway clearinghouse, hopefully to bring user and supplier into a meaningful dialogue wherein the requirements of both might be satisfied.

\section{TECHNICAL STANDARDS AND DATA DEPENDENCE}

Within this context the emphasis by TESLA shall be on technical standards for library automation (e.g., standards relating to electronic data processing devices and techniques). Concurrently, however, there are instances where device and data become inseparably linked. For example, the 
relationship between the physical dimensions of a machine-readable patron badge and the amount and, therefore, type of data which can be mechanically encoded in it; or the character set used by a terminal and the minimum processing potential and, thus, hardware which must be internal to the terminal to receive, transmit, and display that character set. Because it would be foolish to ignore this relationship, TESLA in its clearinghouse function will stress and foster the involvement of individuals or organizational units within the American Library Association wherever data-dependent technical standards are involved.

\section{ALA-ORIGINATED AND MAINTAINED TECHNICAL STANDARDS}

Though certainly no mystery, there is little evidence that the direct cost and personal involvement for a published and practiced standard is popularly known. For example, it has been indicated by those within the standards business that an adopted standard might culminate an investment of over a million dollars and represent the expenditure of tens of man-years. The cost, for example, leading to and including the final publication by the American National Standards Institute (ANSI) of the standard for bibliographic information interchange on magnetic tape (ANSI Z39.21971), more popularly known as MARC, has not been published. It is suspected, however, that the cost of the MARC standard was monumental. In short, and by way of this example, it can be safely assumed that neither the American Library Association nor ISAD nor TESLA will become standards organizations in the strict sense of the word. In fact such a capability is not desirable, since organizations such as ANSI, Electronics Industry Association (EIA), Institute of Electronic and Electrical Engineers (IEEE), National Microfilm Association (NMA), etc., exist and are geared specifically to this activity. Rather, the American Library Association and ISAD should, and must, participate actively in the standards processes available to them to insure a meaningful user-voice in the development of standards by those organizations. To provide for participation in the standards process at the membership level is precisely TESLA's role. Thus, when placed in operation, such standards will reflect the library community's requirements, contributing to and fostering library automation rather than hindering it. At least one of the anticipated results would be the development of equipment addressing library needs directly, and so preclude the custom fabrication of specialty devices which while satisfying the needs of a few libraries-expensively, cannot satisfy libraries in generaleconomically.

\section{WHAT IS PROVIDED BY TESLA?}

TESLA specifically has established a procedure whereby the membership of the American Library Association might either react to proposals for standards regardless of origin, or initiate proposals for standards for membership reaction. The results of this procedure, whether reactive or initia- 
tive, would be communicated to the membership in terms of the status and position taken for each proposal, and to the originator and to ALA's official representative in full detail for subsequent application.

\section{THE TESLA PROCEDURE}

The procedure is geared to handle both reactive (originating from the outside) and initiative (originating from within ALA) standards proposals to provide recommendations to ALA's representatives on existing, recognized standards organizations. To enter the procedure for an initiative standards proposal the member must complete an "Initiative Standards Proposal" using the outline which follows:

\section{Initiative Standard Proposal Outline}

The following outline is designed to facilitate review by both the committee and the membership of initiative standards requirements and to expedite the handling of Initiative Standards Proposals through the procedure.

Since the outline will be used for the review process, it is to be followed explicitly. Where an initiative standard requirement does not require the use of a specific outline entry, the entry heading is to be used followed by the words "not applicable" (e.g., where no standards exist which relate to the proposal, this is indicated by: VI. Existing Standards. Not Applicable).

Note that the parenthetical statements following most of the outline entry descriptions relate to the ANSI Standards Proposal section headings to facilitate the translation from this outline to the ANSI format.

All Initiative Standards Proposals are to be typed, double spaced on $8{ }^{\prime \prime \prime} \times 11^{\prime \prime}$ white paper (typing on one side only). Each page is to be numbered consecutively in the upper right-hand corner. The initiator's last name followed by the key word from the title is to appear one line below each page number.

I. Title of Initiative Standard Proposal (Title).

II. Initiator Information (Forward).
A. Name
B. Title
C. Organization
D. Address
E. City, State, Zip
F. Telephone: Area Code, Number, Extension

III. Technical area. Describe the area of library technology as understood by initiator. $\mathrm{Be}$ as precise as possible since in large measure the information given here will help determine which ALA official representative might best handle this proposal once it has been reviewed and which ALA organizational component might best be engaged in the review process.

IV. Purpose. State the purpose of Standard Proposal (Scope and Qualifications).

V. Description. Briefly describe the Standard Proposal (Specification of the Standard).

VI. Relationship of other standards. If existing standards have been identified which relate to, or are felt to influence, this Standard Proposal, cite them here (Expository Remarks).

VII. Background. Describe the research or historical review performed relating to this Standard Proposal (if applicable, provide a bibliography) and your findings (Justification). 
VIII. Specifications. Specify the Standard Proposal using record layouts, mechanical drawings, and such related documentation aids as required in addition to text exposition where applicable (Specification of the Standard).

Please note that the outline is designed to enable standards proposals to be written following a generalized format which will facilitate their review. In addition, the outline permits the presentation of background and descriptive information which, while important during any evaluation, is a prerequisite to the development of a standard. The Reactor Ballot (Figure 1) is to be used by members to voice their recommendations relative to initiative standards proposals. The Reactor Ballot permits both "for" and "against" votes to be explained permitting the capture of additional information which is necessary to document and communicate formal standards proposals to standards organizations outside the American Library Association. As you, the members, use the outline to present your standards pro-

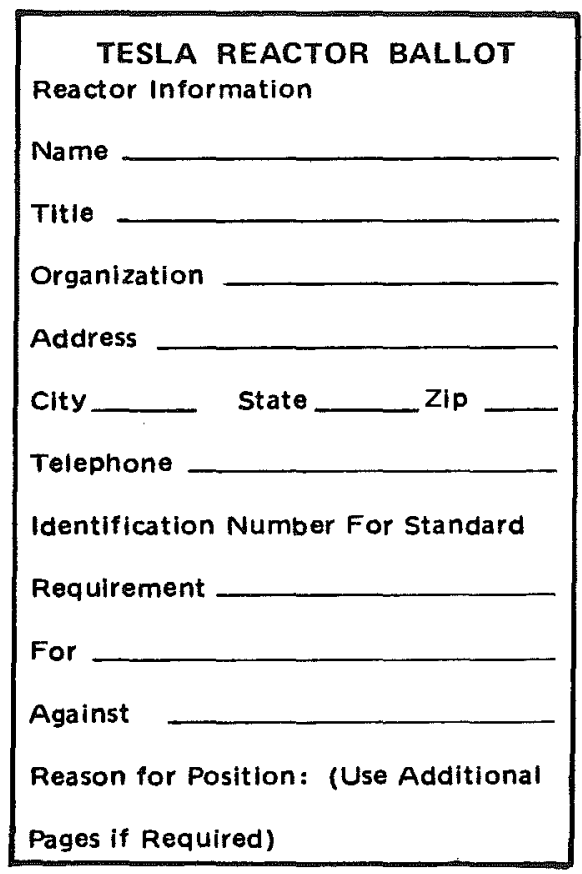

Fig. 1. TESLA Reactor Ballot

posals, TESLA will publish them in JOLA-TC and solicit membership reaction via the Reactor Ballot. Throughout the process TESLA will insure that standards proposals are drawn to the attention of the applicable American Library Association division or committee. Thus, internal review usually will proceed concurrent with membership review. From the review and the Reactor Ballot TESLA will prepare a majority recommendation and a minority report on each standards proposal. The majority recom- 


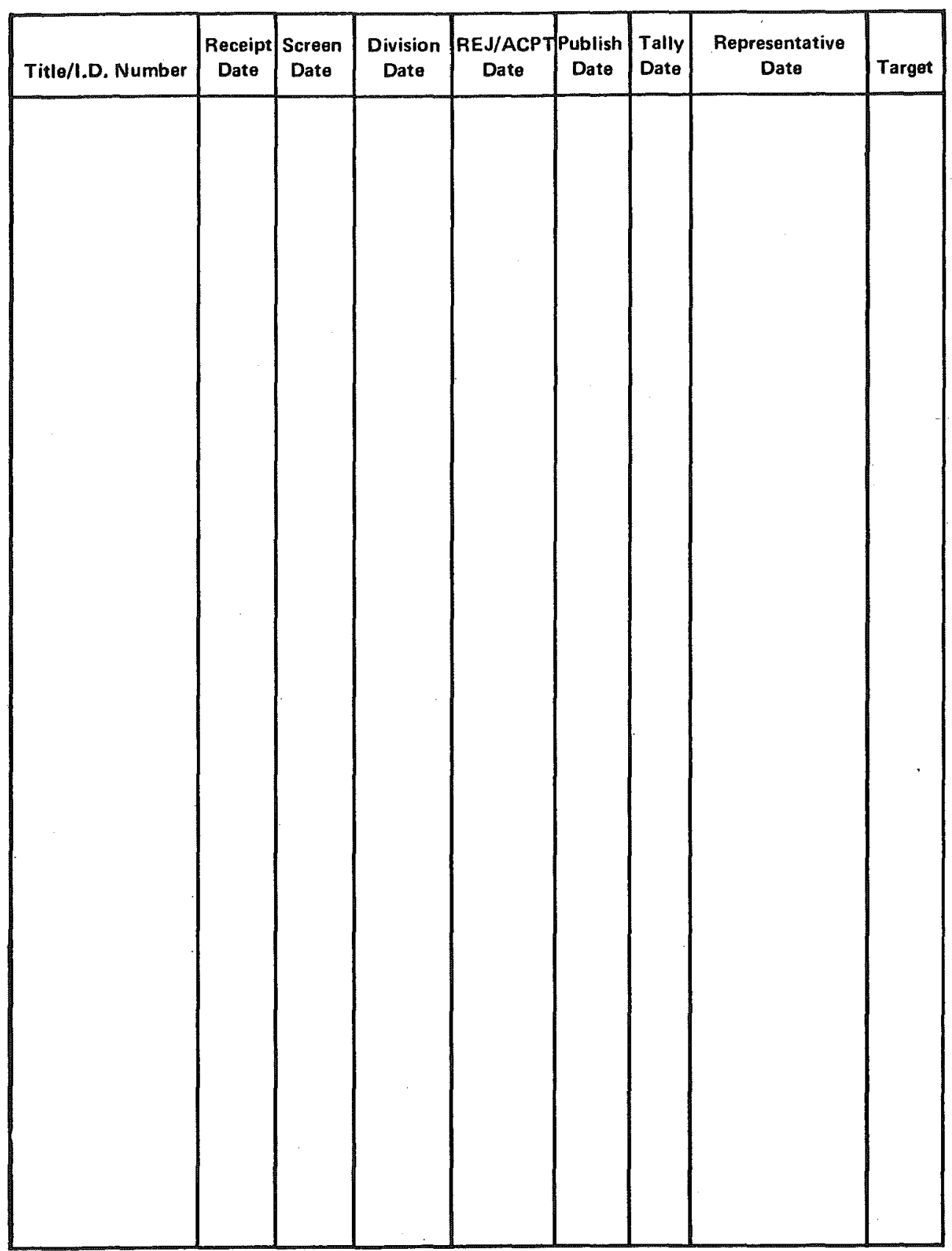

Fig. 2. TESLA Standards Scoreboard

mendation and minority report so developed will then be transmitted to the originator, and to the official American Library Association representative on the appropriate standards organization where it should prove a 
source of guidance as official votes are cast. In addition, the status of each standards proposal will be reported by TESLA in JOLA-TC via the Standards Scoreboard (Figure 2). The committee (TESLA) itself will be nonpartisan with regard to the proposals handled by it. However, the committee does reserve the right to reject proposals which after review are not found to relate to library automation.

\section{TESLA'S COMPOSITION}

TESLA is comprised of representatives both from the library community and library suppliers to insure a mix of both users and producers for its review of standards proposals. In addition, rotating membership on TESLA will insure a continuing movement of voices from different segments of the library and library supplier communities to shortstop the pressing of vested interests. At this time, the members of TESLA and the term for each are:

Ms. Madeline Henderson

Chairperson, Task Force on Automation of Library Operations and Federal Library Committee

U.S. Department of Commerce/NDS

Washington, DC 20234

Term ends: 1974

Mr. Arthur Brody

Chairman of the Board

Bro-Dart Industries

1609 Memorial Ave.

Williamsport, PA 17701

Term ends: 1975

Dr. Edmund A. Bowles

Data Processing Division

International Business Machines Corporation

10401 Fernwood Rd.

Bethesda, MD 20034

Term ends: 1974

Mr. Anthony W. Miele

Assistant Director

Technical Services

Illinois State Library

Centennial Building

Springfield, IL 62706

Term ends: 1975
Mr. Jay L. Cunningham

Director, University-wide Library Automation Program

University of California, South Hall Annex

Berkeley, CA 94720

Term ends: 1976

Mr. Richard E. Uttman

P.O. Box 200

Princeton, NJ 08540

Term ends: 1976

Mr. Leonard L. Johnson

Director of Media Services

Greensboro Public Schools

Drawer V

Greensboro, NC 27402

Term ends: 1975

Mr. John C. Kountz (Chairman)

Associate for Library Automation

Office of the Chancellor

The California State University and Colleges

5670 Wilshire Blvd., Suite 900

Los Angeles, CA 90036

Term ends: 1976

\section{STANDARDS LIBRARY}

In addition to acting as a clearinghouse for standards for ISAD, and the maintenance of the standard proposal and Reactor Ballot procedure, TESLA intends to urge the establishment of an ALA collection of stan- 
dards applicable to libraries to handle requests for information from the library community. Thus, while currently each member is left to "do it himself," there appear to be definite economies in the centralization of such a collection and the periodic publication of indices to relevant standards.

\section{SOURCES OF INFORMATION RELATING TO STANDARDS}

To provide a source of guidance at this time for the types of available standards, to list the many existing standards, and to index the originating standards organizations would consume several issues of JOLA. Therefore, in the following are very brief recapitulations of the more relevant organizations impacting library automation standards. The list is very incomplete as might be expected. For those interested in a comprehensive review of standards, Global Engineering, 3950 Campus Drive, Newport Beach, CA 92660, maintains and annually publishes their Directory of Engineering Document Sources. This directory, now in its second edition, lists over 2,000 standards organizations and the prefixes used by those organizations in publishing their standards, to permit Global Engineering's customers to specify standards for purchase. (Global Engineering's primary function is the sale of original copies of standards and specifications.)

American National Standards Institute, Inc. (ANSI)-The American National Standards Institute, Inc. (1430 Broadway, New York, NY 10019) does not write standards. Rather, ANSI has established the procedures and guidelines to be followed in the development of standards that will be labeled American National Standards: The actual work is done by ANSI members and other interested groups and individuals, using the ANSI procedures in the development of standards. Only after these groups have demonstrated to ANSI's satisfaction that the proposed standard has been developed in accordance with the procedure established by ANSI will it be approved and published as an American National Standard. In addition, ANSI publishes materials relating to standards, of which the ANSI Reporter, a journal dedicated to standards, probably represents the single best source for information relating to current standards issues. However, the scope of ANSI is very broad. Thus for library and library automation activities specific committees of ANSI, rather than ANSI itself, are relevant; specifically, ANSI committees:

PH5 (Microfilm). See National Microfilm Association below.

X3 (Computers and Information Processing); X4 (Business Machines and Supplies). Both of these subcommittees are sponsored by the Computer and Business Equipment Manufacturers' Association (CBEMA), which is also their secretariat. CBEMA (1828 L St. NW, Washington, DC 20036) periodically provides indices to the published standards of X3. An insight into the breadth of X3's activities can be implied from Figure 3, ANSI X3 Standards Committee Organization. X3 currently has 


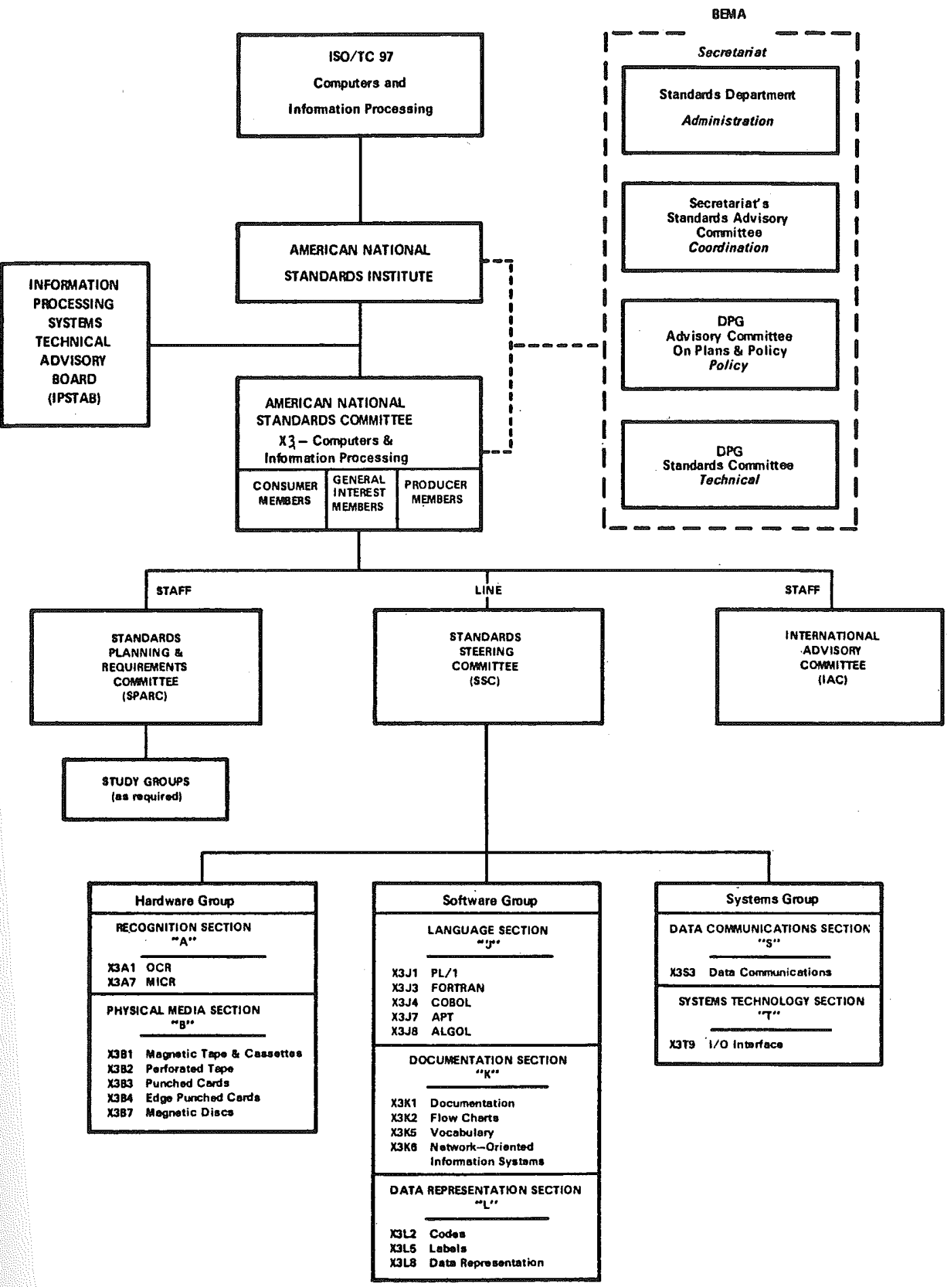

Fig. 3. ANSI X3 Standards Committee Organization. 
over fifty member organizations. The ALA representative on X3 is Mr. James Rizzolo of the New York Public Library.

An excellent overview of X4's scope and activities was published in The Secretary (Nov. 1973) under the title "What's Being Done About Office Equipment Standards." From the library viewpoint X4's activities in credit cards, typewriter keyboards, and forms are of interest. At this writing $\mathrm{X} 4$ has nine user, fifteen producer, and nine general interest members. The ALA is not currently represented on X4.

Z39 (Library Work, Documentation and Related Publishing Practices) sponsored by the Council of National Library Associations. With thirtysix subcommittees (SC), Z39 covers library related activities from machine input records ( $\mathrm{SC} / 2$ ) through standard order forms $(\mathrm{SC} / 36)$. It was through Z39 that MARC became the American National Standard (Z39.2-1971). Z39 publishes a quarterly entitled News About Z39. Z39 is located at the School of Library Science, University of North Carolina, Chapel Hill, NC 27514. Fifteen standards have been published by Z39. The ALA representative to Z39 is Fred Blum of Eastern Michigan University, Ypsilanti, whose excellent summary of Z39 appears in the Winter 1974 issue of Library Resources \& Technical Services.

National Microfilm Association (NMA)-The National Microfilm Association has an organization of standards committees and a standards board as shown in Figure 4. Information relating to their standards is published from time to time in the Journal of Micrographics. A recent article, entitled "Standards: NMA Standards Committee Scope of Work," (Vol. 7, No. 1 [Sept. 1973]), briefly describes the subcommittees internal to NMA's standards organization and the scope of each. Of particular interest to libraries is the sponsorship by NMA of ANSI-PH5. Micrographic standards are listed in an NMA publication (RR1-1974 Resource Report). Copies of this Resource Report may be obtained by contacting the NMA at Suite 1101, 8728 Colesville Rd., Silver Spring, MD 20910.

International Organization for Standardization (ISO)-This organization is truly international with representatives from thirty-five nations. The secretariat of ISO is ANSI (see above). While ISO parallels ANSI in its coverage, it differs organizationally. Thus, the committees/subcommittees of ANSI have in large measure their equivalent technical committees, subcommittees, and working groups in the ISO. Standards developed by the ISO and published by them are reported regularly in the ANSI Reporter (referred to above). Most recently, the January 11, 1974 ANSI Reporter contained an article outlining ISO publications and describing five ISO titles. MARC, by the way, is also ISO standard 2709. The ISO Technical Committees (TC) of immediate interest to library automation are TC 37 (terminology), TC 46 (documentation), TC 95 (office machines), and TC 97 (computers and associated information processing systems, 


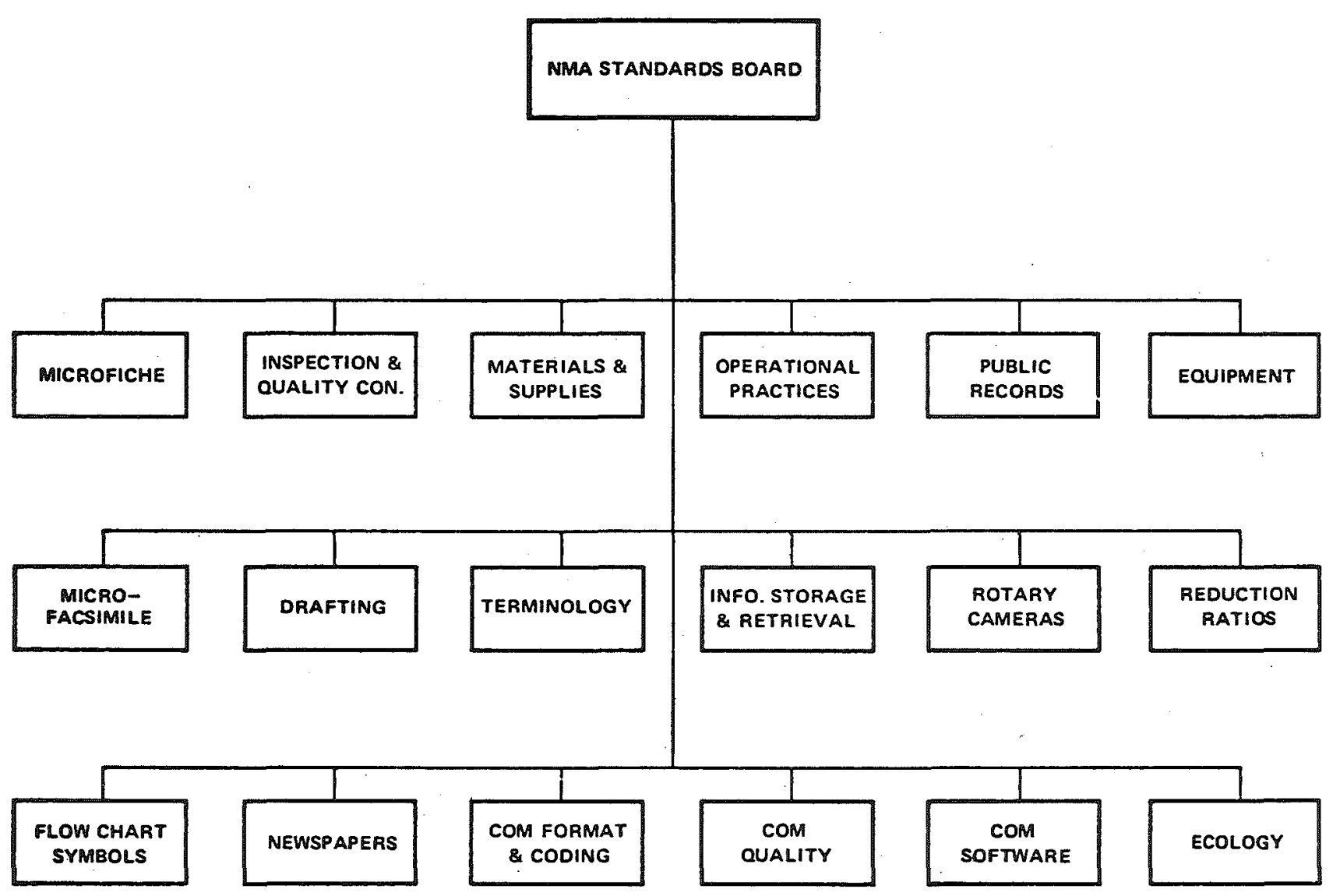


peripheral equipment and devices, and media related thereto). As an indication of the technical areas covered by TC 97 , its organization is shown in Figure 5.

Electronic Industries Association (EIA)-The Electronic Industries Association maintains a broad variety of standards for hardware and related peripheral equipment. Such areas as cathode ray tube (CRT) terminals, the luminescence of cathode ray tubes themselves, television transmission, and data communications are dealt with by the EIA standards. An excellent source of EIA standards is the publication produced by the EIA entitled Index of EIA and JEDEC Standards and Engineering Publications (1973 Revision and No. 2). Copies are available through the Electronic Industries Association, Engineering Department, 2001 I St. NW, Washington, DC 20006. The ALA is not a member of the EIA, by definition.

The Institute of Electronic and Electrical Engineers (IEEE)-The Institute of Electronic and Electrical Engineers, Inc. is a professional organization which, in addition to its professional activities, maintains standards. Many of these standards relate to library automation in such areas as keyboards for terminals and transmission types for data communications. While each monthly issue of the IEEE publication Spectrum contains annotated lists of new standards, a full index to the IEEE standards is available by contacting the IEEE Headquarters, 345 E. 47 St., New York, NY 10017.

National Bureau of Standards (NBS)-The National Bureau of Standards, U.S. Department of Commerce, has the responsibility within the federal government for monitoring and coordinating the development of information processing standards and publishing proved data standards for data elements and codes in data systems. Thus, the National Bureau of Standards works closely with federal departments and agencies, the American National Standards Institute (ANSI), and the International Organization for Standardization (ISO). Of specific interest to library automation are the Federal Information Processing Standards (FIPS) and the FIPS Index published by NBS. The annual FIPS Index (FIPS PUB 12-1) is a veritable gold mine of information relating to ANSI, ISO, federal government participation and representation in the standards process, and the role of NBS itself. FIPS 12-1 is available from the Superintendent of Documents, U.S. G.P.O., Washington, DC 20402 (SD Catalog No. C 13:52: 12-1).

While the material above should provide a brief overview of the standards arena in which TESLA will function and some insight into the scope of standards activities, it is not to be construed as a definitive compilation of standards organizations. As indicated earlier, over 2,000 such organizations are known to be active currently. 


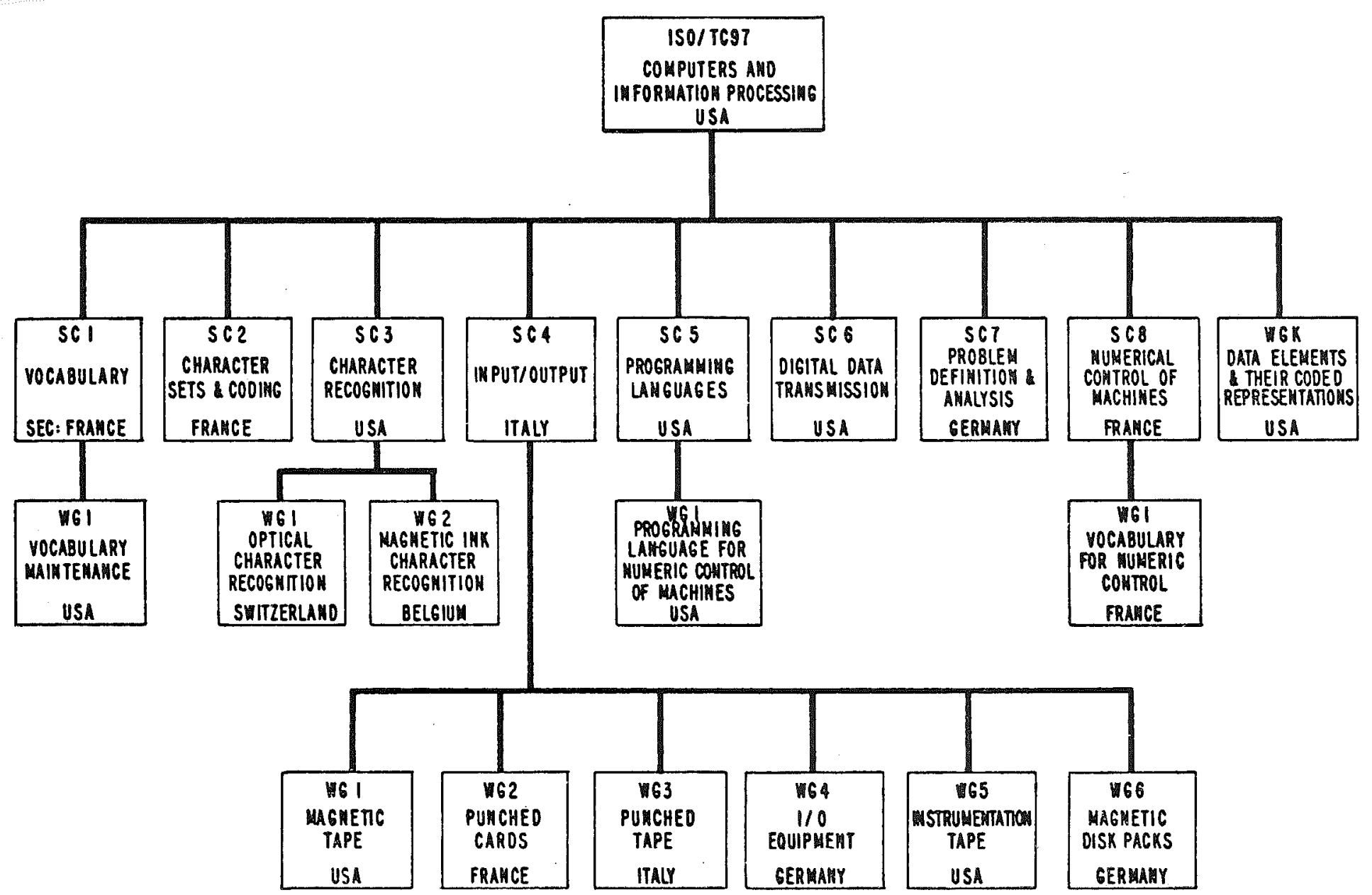

Fig. 5. ISO/TC 97 Organization Chart 


\section{FINALLY, AN INVITATION}

During the formative period of TESLA a list of potential standards areas for library automation was developed.

\section{Potential Technical Standards Areas}

1. Codes for libraries and library networks, including network hierarchy structures.

2. Documentation for systems design, development, implementation, operation, and post-implementation review.

3. Minimum display requirements for library CRTs, keyboards for terminals, and machine-readable character or code set to be used as label printed in book.

4. Patron or user badge physical dimension(s) and minimum data elements.

5. Book catalog layout (physical and minimum data elements):
a. Off-line print
b. Photocomposed
c. Microform

6. Communication formats for inventory control (absorptive of interlibrary loan and local circulation).

7. Data element dictionary content, format, and minimum vocabulary, and inventory identification minimum content.

8. Inventory labels or identifiers (punched cards, labels, badges, or . . .) physical dimensions and minimum data elements.

9. Model/minimum specifications relating to hardware, software, and services procurement for library applications.

10. Communication formats for library material procurement (absorptive of order, bid, invoice, and related follow-up).

You are invited to review this list and voice your opinion of any or all areas indicated by means of the Reactor Ballot in JOLA-TC in this issue. Or, if you've a requirement for a standard not included in this list, use the Initiative Standard Proposal Outline to collect and present your thoughts. Henceforth, future issues of JOLA-TC will contain a Reactor Ballot and the Scoreboard. The ball is in your court!

Send ballots and/or initiative standard proposals to: John Kountz, Chairman, ISAD-TESLA, 5670 Wilshire Blvd., Suite 900, Los Angeles, CA 90036. 